\title{
Investigating cultural influences on investment process in stock exchange
}

\author{
Shamsodin Nazemi, Fariborz Rahimnia, Mohammad Lagzian and S. Morteza Ghayour ${ }^{*}$
}

\begin{tabular}{ll} 
Faculty of Economic and Administrative Science, Ferdowsi University of Mashhad, Mashhad, Iran \\
\hline A R T I C L E I N F O & A B S T R A C T \\
\cline { 2 - 3 } & $\begin{array}{l}\text { Cultural variety is a behavioral characteristic of investors and evaluating the cultural influences } \\
\text { Article history: }\end{array}$ in the area of financial management on the decisions of investors plays an important role. In \\
Received June 20, 2012 & fact, different behaviors and decisions are required in various cultures facing the prices, price \\
August, 20, 2012 & fluctuations and important or non-important published news of portfolio. In this paper, a \\
Accepted 25 August 2012 & questionnaire was designed including 22 cultural items in three criteria of values, facilities and \\
Available online & behavior in order to measure the cultural factors affecting investment in stock exchange. \\
3 September 2012 & Experts' comments were used on the design of items and quintet Likert spectrum was applied \\
\hline Keywords: & for the answers. Structural equation modeling, or multivariable analysis with latent variables, is \\
Value & a comprehensive statistical approach for testing the hypotheses about relationships between \\
Behavior of Investors & observed and latent variables. Such analyzes have been done by LISREL software and the \\
Investment Culture & results showed that there was a significant relationship between investment and its triple factors \\
Cultural Factors & and also between the items and triple factors affecting on investment.
\end{tabular}

\section{Introduction}

Unlike the common paradigm in modern financial theory, which states that the decision makers have a completely rational behavior and pursue the maximization of their properties, the studies in the area of financial behavior indicate that human decision making is not a perfectly rational process and based on all information. However, decision maker applies mental shortcuts in this process, which may result in non-optimal decisions. According to the lack of evaluation of some factors such as cultural variety in financial decisions, the position of such factors is not recognized in decisions of the investors.

Special cultural characteristics of the investors and also their un-awareness of "behavioral financial" traps and capital market and its processes have led the capital market of the country. This is counted as the heart of country' economy to face the lack of dynamism and investors would make mistakes according to the lack of recognition of these factors in making investment decisions. Such mistake will force them to exit from capital market, which could jeopardize the whole economy. 
On the other hand, existing cultural differences among the investors, which can be derived from various factors, lead the occurrence of special behaviors, which are very important either in control or executive system. According to the importance of recognizing cultural factors in making decisions on investment, in this research, 22 cultural items and 3 important factors affecting on the decisions of investors in stock exchange will be evaluated.

\section{Conceptual framework of the research}

Evaluating the culture of investment as the main subject of this research requires representing some definitions of culture. Studying the ideas of some researchers lead to a common definition, which states that culture is a set of common customs, habits, ethics, religion, believes norms, knowledge, actions and reactions of a nation in facing happenings, phenomena, innovations or other social affairs. Regarding the culture of investment, we can say that the position of a phenomenon would not be definite until the cultural contexts exist for its implementation. In other words, the culture of investment is built based on the cultural contexts and dimensions. According to the researchers, different cultural dimensions are as following:

Value System Governing People: General study of the values is known as axiology. In fact, axiology is a reply to three main questions including: whether the values are subjective or objective, whether they are dynamic or constant, and if there is a hierarchy of the values (Robbins \& Judge, 2010). Parsons believes that value is the element of a symbolic system and contains a criterion for measuring the standard in proportionate to the situations (Farhangi, 2008).

Believe in Obligation or Authority: This ides is, in fact, equal to "locus of control", which has been mentioned in the subjects of organizational behavior and refers to the realization of human being of his ability to control the environmental conditions (Ttrotter, 1987). Hence, people have internal locus of control (believe in authority) or external locus of control (believe in obligation) (Schultz \& Schultz, 2008). In fact, introvert people are talented, hard worker and competent; and extrovert people are non-activist, unstable and passive (Singh, 2010).

Optimism or Pessimism: According to the researchers of culture, people are located on two sides of optimism and pessimism as a spectrum. Optimists expect the affairs get done based on their desires and have a positive view of life. On the other side, pessimists insist in their feelings or escape from the problem through envisions (Peterson et al., 1981).

Consumption Pattern (Habit of Saving in People): Habit of saving depends on the interest rate and the rate of risk taking in people. Since in an economy we can gradate all properties based on the measure of their risk, it can be said that deposit is a function of turnover rate of different properties and there is a risk for each one (MirAkhor \& Khan, 1996).

Risk Avoidance or Risk loving: People are classified into three groups of risk-taker, risk-avoider and neutral (Froyen, 2008). Risk lovers are more sensitive to turnover than to the loss; in the other words, the happiness derived from increase in one unit of turnover is more than the sadness of one unit of loss (Pompion, 2002). Risk avoiders associate with changes in condition to undergo the minimum loss. This phenomenon would help the explanation of the tendency of the investors to keep the stock, which has faced the loss, and also rapid sale of the stock which has owned income (Raee \& Talangi, 2004). For the neutral people, happiness and sadness is the same.

Mental Accounting: Mental framework is a part of expectation theory. People with mental accounting are characteristically located in group B. They are very patient, precise and long term oriented (Rezaeian, 2008). They are less risk taker and more look for the stock with stronger support; and also they behave slower than group A (Shahabi, 2006). 
Herding behavior: Acting similar to the congregation or herding behavior is a form of practice creation in which individuals adjust themselves with the decisions of majority of people by following them. In such behavior, in which the personality of people has usually less rationality, is known as low self-confidence, low power of risk taking, too much reliance on market, high flexibility, owning high emotions, the spirit of feminism and lack of tolerating uncertainty.

Over Confidence: Over confidence makes individuals feel themselves higher than the market and believe that they have the information which most people do not have. In fact, such people avoid listening a lot and do not have a wide range of information. They categorize a part of the stock as the growing stock, while ignoring the probability that there are a few companies that grow (Karrabi, 2009).

Need for Achievement: Culture can be classified into two dimensions of avoider and success seeker. In the culture of success seeker, people are active and they look for changes and adjust (Moshabbaki, 1998). In such culture, people pursue achieving success and they are normally located in the phase of self-actualization. In fact, need for achievement leads to more risk taking by the individuals who seek for higher outcome (Rezaeian, 2008).

Interpretation and Perception of Change: This characteristic, which indicates the realization of an individual of the nature of change and development, means that the rate of resistance to change and accepting it may change based on imagination (Taghavi, 2008).

The Sense of Security: The range in which an individual feels secure in the dimensions of legal, economic etc. affects on his behavior. The more someone feels secure, the higher the rate of investment will be; and the less the security, the more cautious and unstable he/she would behave (Karrabi, 2009).

Being Credulous or Incredulous: People are characteristically divided into two classes of credulous and incredulous. Incredulous people are distrustful, with negative mindset (Vaezi, et al., 2008: 11). In contrast, credulous people have healthy and positive mindset about other people and environment. These two groups behave differently in purchasing the stock (Shahabi, 2006).

The Rate of IT Development in Investment: Development of IT is effective on the behavior of investors in business. According to Hatch, physical structure is an important cultural factor, whose kind determines the creation of behavioral model of individuals (Hatch \& Cunliffe, 2006).

The Rate of Awareness in Stock Exchange Mechanisms: Information architect is one of the issues, which affect the behavior of investors in stock exchange. Information banks, websites related to the stock exchange mechanisms in order to information transparency, presenting updated information to the investors and generally the culture of information sharing which results in creation of social capital in the country and organizations, are some factors affecting the stock exchange (Fromlet, 2001).

Rate of Development: Infrastructural development and ease of accessing physical places related to stock exchange and its development, and lack of them on the other side, is another classification of culture that is related to developmental and non-developmental culture. In developmental culture, people can fast and easily access the areas of stock exchange (Karimi, 2001).

Demographic Characteristics: The characteristics such as gender, age, educational level, rate of income and costs, field of study, kind of university, place of university, population of the area and city and so on affect the behavior of investors. Hofsted describes the culture of matriarchy and 
patriarchy in his cultural classification, which confirms that demographic characteristics are culturally effective (Farhangi, 2008).

Pragmatism: Handy (1996) divided the organizational cultures into four groups, one of which is task culture. In such culture, logic-orientation, pragmatism, job validity and problem solving are emphasized; and job and responsibility are valuable. Therefore, the behavior of people could be categorized into two classes of pragmatic and non-pragmatic, in which, the behavior of investors could be analyzed.

Punctuality: People are divided into two groups of punctual and non-punctual. In punctuality culture, people go to work and exit on time and do care about it. Two kinds of behavior could be defined based on these cultures. Punctual people are highly planned and precise and respect the bureaucratic behavior (Kreitner \& Kinicki, 2008).

Being Active or Passive: Regarding social behavior, people could be divided into two groups of active and passive. Active people are risk taker, spontaneous, warm and kind, adventurer and own an independent entrepreneur personality. In contrast, passive people are dependent, risk avoider, follower and move with the wave. Such characteristics create two different behaviors of investors (Shahriari, 2007).

Being Arithmetic: Mac Holland divided people into six characteristic - cultural groups, one of which is traditionalism and the other is the art that enables mentioning them. Traditionalists are efficient, pragmatic, inflexible, arranged and highly précised. They measure everything quantitatively and are less dependent on personal emotions. In stock exchange, these people buy and sell the stock with high arithmetic (Gholi Pour, 2008).

Role Taking and Having Transitional Character: Cultures are categorized to four groups based on the environmental complexity, two of which are flexibility culture and process culture. In flexibility culture, there exists role taking and having transitional character in which people adjust themselves with different environmental changes, while in process culture, some characteristics of people include doing similar tasks, inflexibility and enjoying steady jobs (Daft, 2009).

\section{Methodology of Research}

Since the aim of this study is to identify the factors affecting the investment in stock exchange, it is a descriptive applied research based on Structural equation modeling. Structural equation modeling or multi-factor analysis with latent variables is a comprehensive statistical approach to examine the hypotheses about the relationships between observed and latent variables. In the research model, the indicators constituting the factors of investment in stock exchange were defined and their effect was determined. Questionnaire was selected as the main tool for data collection. A questionnaire was designed including 22 in order to measure the factors affecting investment in stock exchange. The ideas of experts and also the Likert spectrum were used in designing the items.

\subsection{Hypotheses and Variables of the Research}

There are three main hypotheses in this research as follows,

a. There is a significant relationship between cultural values of investors and kind of investment.

b. There is a significant relationship between personal behaviors of investors and kind of investment.

c. There is a significant relationship between available facilities for the investors and kind of investment. 
A sample including 30 questionnaires were pre-tested in order to check the reliability and was calculated as 0.86 using collected data and Chronbach' alpha. This measure shows that the questionnaire is reliable. In order to test the validity of the questions (items), factorial validity method was used. Factorial validity is a sort of the construct validity, which is obtained through factor analysis. Factor analysis is a statistical technique that has many applications in the humanities. In fact, factor analysis is essential for the areas in which questionnaire and test exist and the variables are latent. Factor analysis is used with two approaches of exploratory and confirmatory. Since the tool of this study is researcher's made, exploratory factor analysis was used for identifying the factors and formulating the model. Table 1 shows the measure of KMO (Kaiser-Meyer-Olkin) resulted from confirmatory factor analysis and also the significance number of Bartlett's test.

Table 1

Measure of KMO

\begin{tabular}{ccc}
\hline \multicolumn{3}{c}{ KMO and Bartlett's Test } \\
\hline Kaiser-Meyer-Olkin Measure of Sampling Adequacy. & .649 \\
\hline \multirow{2}{*}{ Bartlett's Test of Sphericity } & Approx. Chi-Square & 596.443 \\
& Df & 231 \\
& Sig. & .000 \\
\hline
\end{tabular}

According to the significance number of Bartlett's test $(\mathrm{P}<0.005)$, it could be resulted that the data have a suitable validity. Fig. 1 shows Screen plot, resulted from factor analysis indicates that after the third factor, the Screen plot finds a horizontal slope, which shows that the questions of the research indicate three principal components.

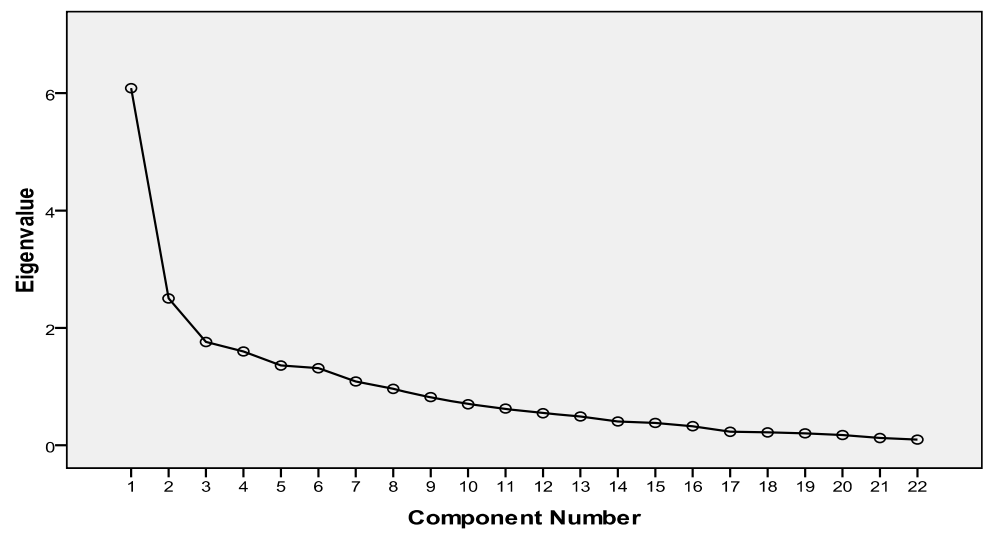

Fig. 1. Screen plot, resulted from factor analysis indicates

Therefore, the items of research are put in three main factors which are named "values", "facilities" and "behavior" respectively (with 9, 4 and 9 items respectively) according to the related items. These items are, in fact, the three main identified factors affecting Khorasan Razavi investors of Stock Exchange. The population of research is 200. Random sampling method was used, as the sampling framework and involvement of behavioral variables for all members of population were specified. Variance was 0.15 in pre-test for a sample of 30 respondents. Based on sampling formula from limited population and $\mathrm{e}=0.075$ and $\alpha=0.05$, a sample of 61 respondents were selected and 75 questionnaires were distributed with $80 \%$ rate of return.

$$
n=\frac{N Z_{\alpha / 2}^{2} \sigma^{2}}{\varepsilon^{2}(N-1)+Z_{\alpha / 2}^{2} \sigma^{2}}, n=\frac{200 \times 1.96^{2} \times 0.15}{0.075^{2}(200-1)+1.96^{2} \times 0.15} \approx 61
$$




\section{Results}

Demographic evaluation of the sample indicates that $51.2 \%$ of the respondents are men, $2 \%$ have masters degree, $63 \%$ bachelors, $6 \%$ associate degree and others diploma and less. $18 \%$ of the respondents have been attendants, $43 \%$ have less than 10 years of job experience, $13 \%$ more than 20 and $34 \%$ between 10 and 20 . Age of $7 \%$ of respondents was less than $25,81 \%$ between 25 and 45 and $12 \%$ were more than 45 . Fig. 2 shows the structural model of the research in standard position which was measured by Lisrel software. The structural model indicates that three factors of "values", "facilities" and "behavior" affect on investment in Khorasan Razavi investors of Stock Exchange with measures of $0.81,0.55$ and 0.86 respectively. The measure of proportion indexes of this model are: $\mathrm{X}^{2} / \mathrm{df}=2$ and $\mathrm{RMSE}=0.076$. Totally, in the model of structural equations, if the measure of RMSEA is less than 0.05, it would be a good model and if it is between 0.05 and 0.08 , the model would be suitable. In this research, the model is in suitable condition regarding the measure of RMSEA. (Fig. 2).

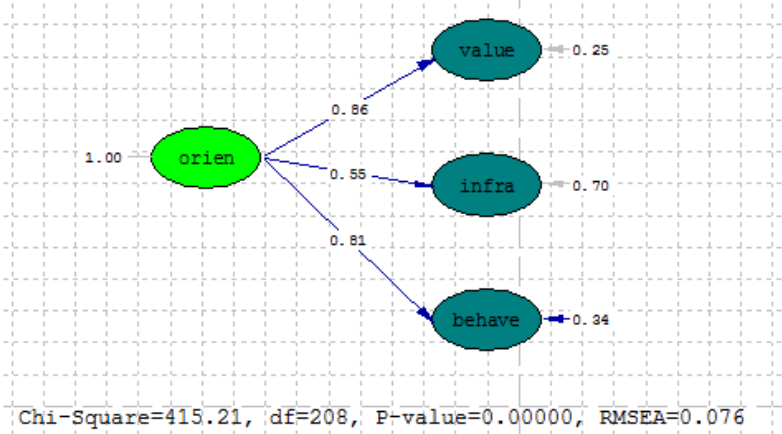

Fig. 2. Measure of RMSEA

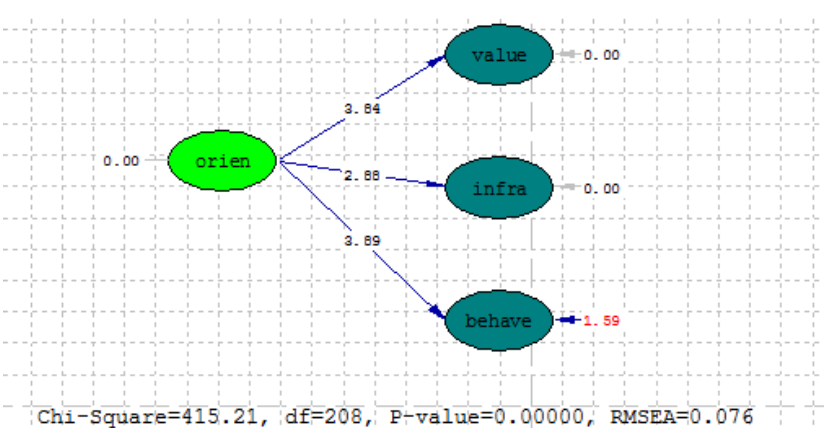

Fig. 3. structural model of research

Fig. 3 shows the structural model of research in significance position, which indicates that all three so-called measures are significant in $\mathrm{P}<0.05$. Fig. 4 shows the measurement model through combining three factors (or latent variables) with 22 items (or question: observed variables). As it is seen in this model 9 items belong to "values", 4 items to "facilities" and 9 items to "behavior". It is seen in measurement model that values are correlated with facilities and behavior with 0.47 and 0.7 respectively and also there is a correlation between facilities and behavior with 0.44 .

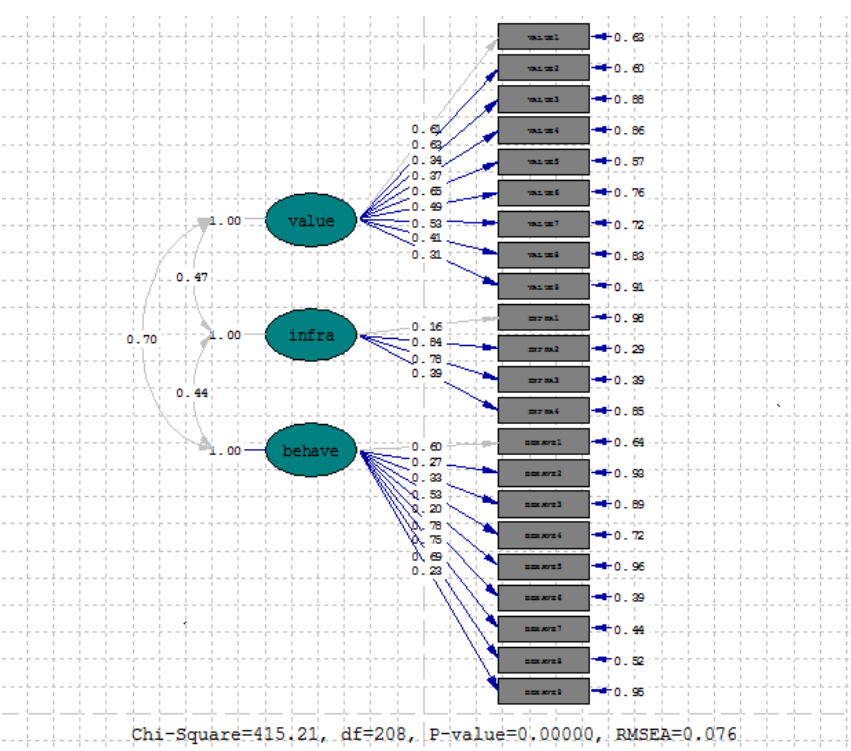

Fig. 4. detailed structural model

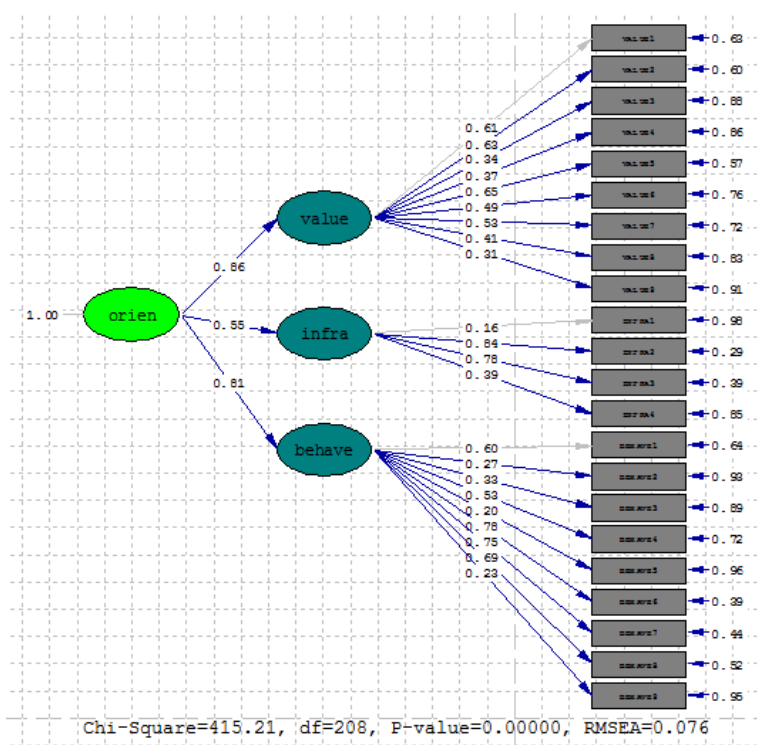

Fig. 5. total structural model 
Total model of research in standard position, in which measurement model and structural model have been presented simultaneously designed in Fig. 5. Fig. 6 shows total model of research in significance position. As it is seen, the relation between investment and its triplet factors is significant. In addition, there is a significant relation between items and triplet factors affecting investment $(\mathrm{P}<0.05)$. Only the questions 3, 5 and 9 are somewhat far from significance (1.96), and belong to "behavior".

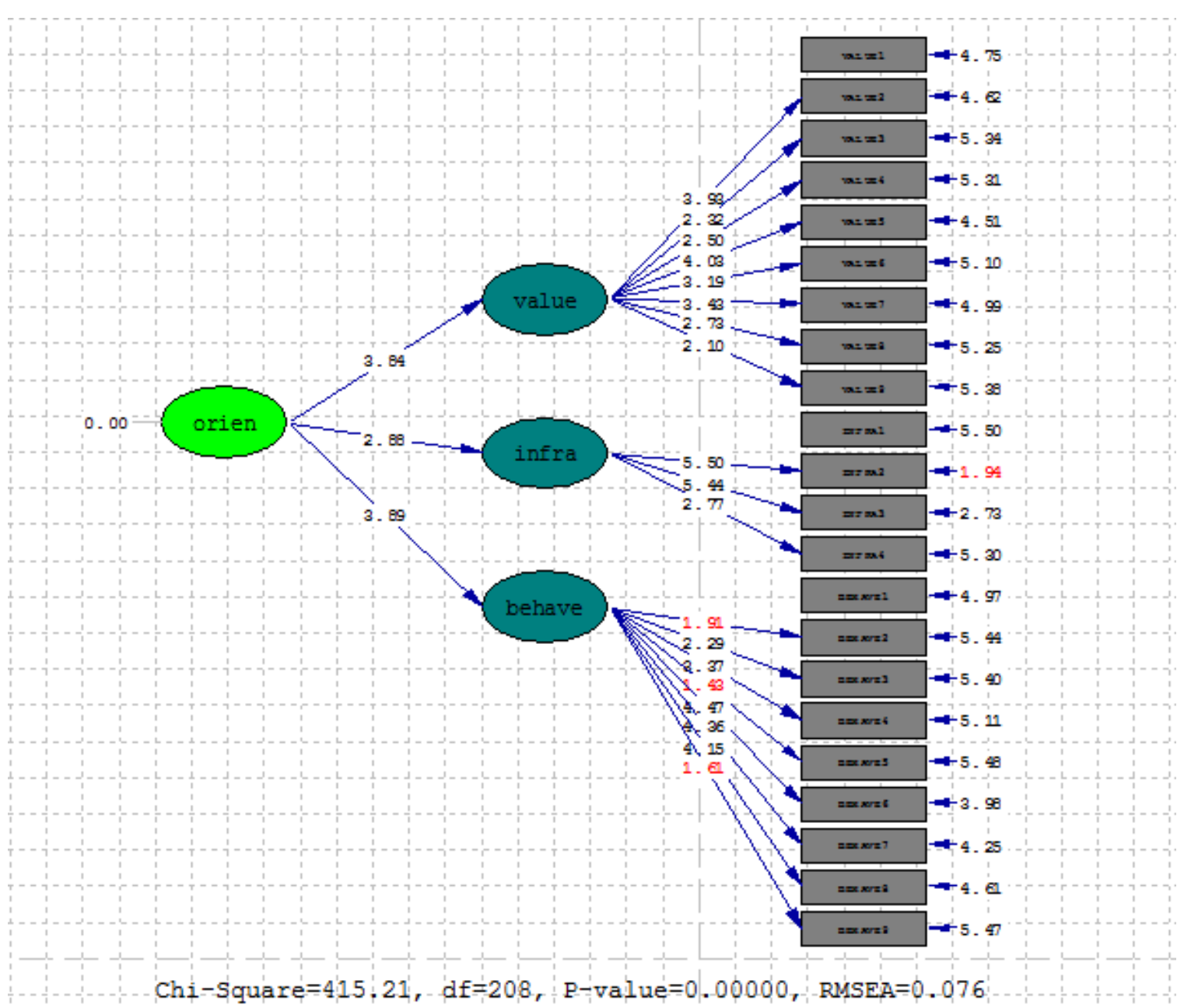

Fig. 6. Total model of research in significance position

\section{Conclusion}

In this study, a questionnaire was designed with 22 cultural items in three factors of values, facilities and behavior in order to measure the cultural factors affecting investment in stock exchange. The ideas of experts were used on the design of items and quintet Likert spectrum was applied for the answers. Structural equation modeling, or multivariable analysis with latent variables, is a comprehensive statistical approach for testing the hypotheses about relationships between observed and latent variables. The so-called analyzes were done by LISREL software and the results confirmed the hypotheses of the research. The results of the relations of cultural types, factors and decisions of the investors are as following:

1) Three factors of values, facilities and behavior affect on investment in Khorasan Razavi investors of Stock Exchange with 0.86, 0.55 and 0.81 , respectively.

2) As it is seen in the model, 9 items belong to "values", 4 items to "facilities" and 9 items to "behavior". It is seen in measurement model that values are correlated with facilities and behavior with 0.47 and 0.7 respectively and also there is a correlation between facilities and behavior with 0.44 . 
3) The relation between investment and its triplet factors is significant; and also there is a significant relation between items and triplet factors affecting investment $(\mathrm{P}<0.05)$. Only the questions 3,5 and 9 are somewhat far from significance (1.96), and belong to "behavior".

These results confirm that cultural differences of the investors are effective on their decisions in stock exchange.

\section{References}

Daft, R.L. (2009). Organization Theory and Design. South-Western College Pub., $10^{\text {th }}$ ed.

Farhangi, A. A. (2008). Theorists and Notables of Management: Tehran, Entrepreneurship Center of Tehran University. $3^{\text {rd }}$ ed., 198-205.

Fromlet, H. (2001). Behavioral Finance, Theory and Practical Application. Business Economies. $3^{\text {rd }}$ Ed. P. 12-19

Froyen, R.T. (2008). Macroeconomics. 9th Ed., Prentice Hall.

Gholi Pour, A. (2008). Management of Organizational Behavior. Individual Level: Tehran, Samt, $1^{\text {st }}$ Ed. P. 189. (In Persian).

Handy, C.B. (1996). Gods of Management: The Changing Work of Organizations. Oxford University Press.

Jo Hatch, M., \& Cunliffe, A.L. (2006). Organization Theory: Modern, Symbolic, and Postmodern Perspectives. Oxford University Press.

Karimi, A. (2001). Financial Development and Saving Behavior in Iran: Shiraz, University of Shiraz, Master's Thesis. P. 103-111. (In Persian).

Karrabi, M. (2009). Evaluating the Behavioral - Financial Traps in Tehran Stock Exchange: Tehran, Emam Sadegh University, Master's Thesis. P. 89-97 (In Persian).

Kreitner, R., \& Kinicki, A. (2008). Organizational Behavior. Mc Graw Hill, $8^{\text {rd }}$ Ed. P. 67-73

MirAkhor, A., \& Khan, M. (1996). Theoretical Studies in Islamic Financial and Banking. Imam Sadeq university, $1^{\text {st }}$ ed., 27-32. (In Persian).

Moshabbaki, A. (1998). Management of Organizational Behavior, Value - Applied Analysis of Development Organizational Behavior: Tehran, Termeh. $2^{\text {nd }}$ Ed. P. 121-136 (In Persian).

Peterson, C., Schwartz. S.M., \& Seligman M.E.P. (1981). Self-blame and depressive symptoms. Journal of Abnormal and Social Psychology, 41, 339-358.

Pompion, M. M. (2002). Behavioral finance and wealth management. Willy finance. $5^{\text {rd }}$ Ed. 250-263

Raee, R., \& Talangi, A. (2004). Management of Advanced Investment: Tehran, Samt, $1^{\text {st }}$ Ed. 135, (In Persian).

Rezaeian, A. (2008). Fundamentals of Organizational Behavior: Tehran, Samt, $5^{\text {th }}$ Ed. P. 257-263 (In Persian).

Robbins, S.P., \& Judge, T.A. (2010). Organizational Behavior Prentice Hall. $14^{\text {th }}$ ed.

Schultz, D.P., \& Schultz, S.E. (2008). Theories of Personality. 9th ed., Wadsworth Publishing.

Shahabi, Z. (2006). Evaluating the A/B Personality Types and Optimism - Pessimism in Employees of Tehran Governmental Organizations: Tehran, Alzahra University, Master's Thesis. P. 164-170 (In Persian).

Shahriari, S. (2007). Evaluation and Testing the Massive Behavior of Investors through Deviations of Stock Returns from Total Market Yield in Tehran Stock Exchange During 2001 to 2005: Tehran, Tehran University, Master's Thesis. P. 234-236 (In Persian).

Singh, S. (2010). Sociology of Development. Rawat Publications.

Taghavi, S. A. (2008). Identification and Formulation of Cultural Indexes of Investment and Their Effect on Investment in Tehran Stock Exchange: Tehran, Emam Sadegh University, Master's Thesis. P. 61 (In Persian).

Ttrotter, R. (1987). Stop blaming yourself. Psychology Today, 35, 180-200. 